The Egyptian International Journal of Engineering Sciences \& Technology, Vol 4, No 1 (2000)

\title{
Discharge Equation For Free Flow Below Gates Upstream Sloping Diverging Chaimel Reach
}

A negm, G.M Abdel-Aal, A.A Ibrahim, A.A El-Saiad

\begin{abstract}
The characteristics of discharge below gates upstream radial stilling basin in sloping channels have been discussed by same authors. In this research, a generalized discharge equation was developed for free flow below gates upstream radial stilling basins in both horizontal and sloping channels based which based on large series of experimental data. The data were collected using a laboratory flume using different expansion ratios ranging from 0.33 to 0.745 . Accordingly, different basin lengths were used. The developed equation predicted the discharge with maximum error of $\pm 1 \%$.
\end{abstract}

